that there were no technical set-up problems that could have accounted for the observed failures, we reported the problems that were identified to the manufacturers and invited comment.

None of the systems produced alerts for all of the 18 scenarios (table). In terms of prescription of drugs with similar names, none of the systems warned for all 10 drug pairs considered.

The evaluators produced no discrepancies in assessing the safety of systems. Each of the four system suppliers agreed with our assessments.

\section{Comment}

The safety features of computing systems currently in use in about three quarters of UK general practices have clinically important deficiencies. All may fail to warn in a situation when a warning is expected, thus potentially creating a health hazard to patients.

One solution to this problem is to have more explicit regulations about the situations in which suppliers should implement specific alerts. Because information technology, pharmacology, and medicine are dynamic fields, suppliers of systems and drug databases would need to have regular dialogue with end users about ways of further improving the safety features of these important aides to clinical management. Our discussions with manufacturers indicate that many of the problems uncovered could be resolved, and this work is now being taken forward by the National Patient Safety Agency.

We thank the PRIMIS staff for help with the system set up for the evaluation, GP computer system suppliers for responding constructively to our work, and Judy Cantrill and Caroline Morris for their involvement in the Delphi exercise. This work formed a part of BF's MSc thesis which was co-supervised by Dipak Kalra of CHIME, University College, London.

Contributors: AA and BF conceived the study, all authors were involved in study design, $\mathrm{BF}$ and $\mathrm{BS}$ tested the computer systems, all authors were involved in the analysis, and BF, BS, AS, and AA wrote the paper. AA is guarantor.

Funding: National Patient Safety Agency.

Competing interests: Until October $2002 \mathrm{MAB}$ was paid as a medical consultant to Torex Health.

Ethical approval: Not required.

1 Department of Health. Delivering 21st century IT support for the NHS: national strategic programme. London: Department of Health, 2002. www.dh.gov.uk/assetRoot/04/06/71/12/04067112.pdf (accessed 23 www.dh.gov.

2 Magnus D, Rodger S, Avery AJ. GPs' views on computerised drug interaction alerts: questionnaire survey.J Clin Pharm Ther 2002;27:377-82.

3 Yen-Fu C, Avery AJ, Neil K, Johnson C. Assessing the occurrence and preventability of prescribing potentially hazardous/contraindicated drug combinations in general (family) practice. Pharmacoepidemiol Drug Safety 2001;10:S53.

Wilson T, Sheikh A. Enhancing public safety in primary care. BMJ 2002;324:584-7.

5 Avery AJ, Savelyich B, Teasdale S. Improving the safety features of general practice computer systems. Informatics Prim Care 2003;11:203-6.

(Accepted 25 March 2004)

\title{
Commentary: Computer aided prescribing leaves holes in the safety net
}

\author{
R E Ferner
}

West Midlands Centre for Adverse Drug Reaction Reporting, Cit Hospital, Birmingham B18 7QH

R E Ferner director

r.e.ferner@ bham.ac.uk
Patients die from poor prescribing. As with so much else, poor communication is a major culprit. Amoxil (amoxicillin) is misread as Daonil (glibenclamide) because of bad handwriting; 10U is interpreted as 100 [units] because of inappropriate abbreviation; patients are overdosed with a standard release drug when a modified release formulation was intended but not specified. ${ }^{1}$ The prescribing process is complex, and opportunities for error abound. Patients may be given drugs they are allergic to, or which are contraindicated or have already been prescribed under another name; one drug may interact with another; the dosage, or duration, or formulation, or route may be wrong: in short, anything that can go wrong in prescribing will go wrong.

Computers can help. They reduce medication error rates by as much as $60 \%$ simply by ensuring that prescriptions are legible, complete, and in a standard format. ${ }^{2}$ That is encouraging, but patients still die from the remaining errors. The NHS Information Authority requires that systems used in general practice "shall cross check prescriptions for known sensitivities, interactions and active ingredient duplications in the patient record. An appropriate warning to the prescriber shall be given."
But GP prescribers put their trust in these systems at their patients' peril. Fernando and colleagues tested four computer prescribing systems. ${ }^{4}$ One failed to meet the NHS requirements; others failed to warn of potentially serious prescribing errors, especially where drugs were contraindicated. Contraindications account for about $4 \%$ of adverse drug events in general practice. ${ }^{3}$

The systems could be improved. They might list every contraindication to a drug whenever it was prescribed. That change would trap more errors but risk overwhelming the user with alerts: primary care physicians ignore alerts from nagging computers. ${ }^{5}$ Relevance is the key. Prescribers need not be reminded constantly that etoricoxib is contraindicated in inflammatory bowel disease, that nalidixic acid should be withheld from patients with epilepsy or porphyria, or that hyoscine- $N$-butylbromide should be avoided in patients with myasthenia gravis. Yet timely and relevant warnings will prevent disaster. Hospital systems already exist that link patient history, laboratory results, and prescribing data and that present a hierarchy of warnings to inform, advise, and occasionally forbid the prescriber to continue. ${ }^{6}$ 
No human activity is error-free, and we have recognised belatedly that prescribing is complex and prone to error. We need to make it safer-which means increasing the chances that important errors will be avoided or caught by checks before they are translated into harm. We can and should ensure that prescribers-who now include nurses and pharmacists-learn to use medicines safely. Practical examinations in the core skills of therapeutics should help. ${ }^{1}$ That will still leave patients vulnerable to prescribers' human failings. Computers can improve communications by generating a legible and complete prescription. But Fernando and colleagues show that several widely used systems fail to detect known prescribing errors. Those who walk the therapeutic tightrope in general practice will want the assurance of a safety net that will catch important errors before they harm patients, an assurance that current systems cannot provide.

Competing interests: REF is a member of the Medicines Management Working Group of the NHS Information Authority.

1 Smith J. Building a safer NHS for patients: improving medication safety. London: Department of Health, 2004.

2 Anderson JG, Jay SJ, Anderson M, Hunt TJ. Evaluating the capability of information technology to prevent adverse drug events: a computer simulation approach. J Am Med Inform Assoc 2002;9:479-90.

3 Australian Department of Health and Ageing. Better medicines management systems. Drug alerts discussion paper Version 3.0,11 June 2009. management systems. Drug alerts discussion paper. Version 3.0, 11 June 2002.

4 Fernando B, Savelyich BSP, Avery AJ, Sheikh A, Bainbridge M, Horsfield $\mathrm{P}$, et al. Prescribing safety features of general practice computer systems: $\mathrm{P}$, et al. Prescribing safety features of general practice comput
evaluation using simulated test cases. BMJ 2004:328:1171-2.

5 Weingart SN, Toth M, Sands DZ, Aronson M, Davis RB, Phillips RS. Physicians' decisions to override computerized drug alerts in primary care. Arch Intern Med 2003;163:2625-31.

6 Nightingale PG, Adu D, Richards NT, Peters M. Implementation of rules based computerised bedside prescribing and administration: intervention study. $B M J$ 2000;320:750-3.

\section{When I use a word}

\section{HARMful reactions}

During the second world war Leopold Meyler, a Dutch physician, developed pulmonary tuberculosis. He later received treatment and suffered an adverse reaction: either dihydrostreptomycin made him deaf or para-aminosalicylic acid made him feverish-the details are disputed. But it stimulated him, bedbound, to retrieve published reports of unwanted effects of drugs and to collect them in a volume that ran to 192 pages and was first published in Dutch in 1951 (Schaldelijke Nevenwerkingen van Geneesmiddelen). An English translation (Side Effects of Drugs) appeared in 1952, and several updates followed. When Meyler died suddenly in 1973, while preparing volume 8, Graham Dukes took over the editorship, started publishing the updates annually (Side Effects of Drugs Annuals), and created an encyclopedic version, Meyler's Side Effects of Drugs.

The title Side Effects of Drugs has stuck, through 14 editions of the encyclopedia and 26 volumes of the annual. But we now recognise that side effects of drugs, as well as toxic effects and hypersusceptibility effects, are particular forms of unwanted effects, and that the term "adverse effects" is preferable (Lancet $2000 ; 356: 1255-60)$. A toxic effect is one that occurs at high doses, by exaggeration of the desired therapeutic effect. For example, a cardiac arrhythmia due to digoxin is a toxic effect-it occurs by the same mechanism as the therapeutic effect.

On the other hand, an unwanted side effect (or, better, a collateral effect; see BMJ 2003;327:1222-5) occurs at the usual therapeutic dose, usually in some tissue other than the site of the therapeutic effect, and sometimes via some non-therapeutic mechanism. For example, the anticholinergic effect of a tricyclic antidepressant is a side effect, since this action is not responsible for the therapeutic effect. Impaired colour vision caused by sildenafil inhibiting phosphodiesterase type $\mathrm{V}$ in the eye is a side effect, since the phosphodiesterase you want to inhibit is in the corpora cavernosa.

Side effects may also be beneficial rather than harmful. For example, treating hypertension with a $\beta$ blocker may, by $\beta$ blockade, also relieve angina, a beneficial side effect. Alternatively, a depressed patient with irritable bowel syndrome may incidentally benefit from the anticholinergic side effect of a tricyclic antidepressant as well as from its antidepressant action.

Finally, hypersusceptibility effects typically occur at low doses and are often immunological in mechanism. The term "adverse effect" encompasses all these types of unwanted effects and makes no assumptions about mechanism or relation to dose.

Now, talking about adverse effects looks at things from the point of view of the drug. But it has instead become common to talk about "adverse reactions," looking at them from the point of view of the patient, and specifically about "adverse drug reactions" (ADRs). However, the term "drug" excludes contaminants (such as in herbal medicines) or supposedly inactive excipients in a formulation. And so, recognising that medicinal products contain ingredients other than active principles, I propose that we should talk about adverse reactions to medicines or medicaments, ARMs rather than ADRs. And don't we all want a farewell to ARMs?

And since Meyler's book is soon to appear in electronic format, with the provisional title Meyler's International Encyclopedia of Adverse Drug Reactions, I like to regard its database as Highlighting Adverse Reactions to Medicines. And where's the HARM in that?

Jeff Aronson clinical pharmacologist, Oxford

We welcome articles up to 600 words on topics such as A memorable patient, A paper that changed my practice, $M y$ most unfortunate mistake, or any other piece conveying instruction, pathos, or humour. Please submit the article on http://submit.bmj.com Permission is needed from the patient or a relative if an identifiable patient is referred to. We also welcome contributions for "Endpieces," consisting of quotations of up to 80 words (but most are considerably shorter) from any source, ancient or modern, which have appealed to the reader. 